\title{
DEVELOPING TRANSLATION COMPETENCE IN THERMAL POWER ENGINEERING STUDENTS
}

\author{
Ksenia Girfanova ${ }^{1, *}$, Nikolay Kachalov ${ }^{1}$, and Inna Cheremisina Harrer ${ }^{1}$ \\ ${ }^{1}$ National Research Tomsk Polytechnic University, 634050 Tomsk, Russia
}

\begin{abstract}
An engineering graduate today should be able to apply a variety of professional and the so-called deep learning competences including communication and translation competence. The paper gives a review of the notion of translation competence and presents key pre-requisites and creative tasks that enable thermal power engineering students of the National Research Tomsk Polytechnic University, Russia, develop and master translation competence.
\end{abstract}

\section{Introduction}

An engineering graduate of the $21^{\text {st }}$ century should demonstrate a wide variety of skills and competences to be eligible to fit in the modern context of the international labour market. New pedagogies for deep learning that are available in the $21^{\text {st }}$ century are aimed at training specialists prepared to work creatively in the global economic community and respond to the unpredictable challenges of the time for the sake of the stable and sustainable development [1,2].

Deep learning skills (also termed as $21^{\text {st }}$ century skills and competencies) are composed of four groups of skills, which include ways of working: communication and collaboration; ways of thinking: critical thinking, problem solving and metacognitive skills; tools for working: information and communication literacy; and ways of living in the world: global citizenship and civil responsibility, as well as cultural awareness and competence [3]. Communication is understood in a very broad sense, including communication in the native language as well as in the second (or foreign) language, which supposes using both languages as a means of communication and for the purposes of direct and inverse translation. In this case the translator plays an important social function of the mediator between the two languages and two cultures.

In 1997 the PACTE research group (Process in the Acquisition of Translation Competence and Evaluation) was formed in Spain with the purpose to investigate the notion of translation competence and evaluate how translation competence can be acquired based on experimental studies involving the process of written translation [4]. In 2000 the group formulated that translation competence is understood as a system of knowledge and skills needed to be able to translate [5]. Later the notion 'translation competence' was deepened by the following important characteristics constituting it. Firstly, it is seen as expert knowledge and not possessed by all bilinguals; secondly, it is basically procedural

\footnotetext{
* Corresponding author: kcheremisina@tpu.ru
} 
knowledge (and not declarative); thirdly, it is made up of various interrelated subcompetences; and fourthly, the strategic component is very important [6]. In translating practice most processes should be automatic, and the strategy guides the translator in choosing the right and appropriate way of solving translation problems.

Applying the PACTE model of translation competence to the reality of written translation fulfilled by thermal power engineering students, we should focus on the following key aspects (also termed as translation sub-competences) that provide efficient acquisition of translation competence. To be bilingually fluent the translator needs to be more or less expert in Russian and English and demonstrate pragmatic, socio-linguistic, textual and lexical-grammatical knowledge of both languages. Taken together the above components constitute the bilingual sub-competence. Subject knowledge that is deep understanding of the professional area as well as theory and practice of translation, the knowledge of two cultures, and eventually general encyclopedic knowledge provide the basis for the extra-linguistic sub-competence. Closely linked with the second subcompetence stands the instrumental sub-competence that involves the use of referential and documentation sources (dictionaries, encyclopedias, electronic corpora, terminological databases, etc) and application of information and communication technologies. The strategic sub-competence embraces the all above sub-competences and ensures the effectiveness of the translation process. Finally, the emphasis in PACTE's model is made on the transfer sub-competence, which includes understanding of the source text and reexpressing its idea in the target language.

The model of translation competence developed by the PACTE research group goes in parallel with the standards elaborated and being implemented in the professional translation activity in Europe. According to the European standard requirements translator's professional competences include translating competence; linguistic and textual competence in the source language and the target language; research competence, information acquisition and processing; cultural competence; and technical competence [7]. The article evaluates the key pre-requisites that are needed to develop translation competence in thermal power engineering students and gives an overview of the creative tasks that promote to master the acquired translation competence at a more advanced level of study.

\section{Key pre-requisites for developing translation competence in thermal power engineering students}

To become an efficient translator the student should possess good knowledge and skills in both languages - Russian and English. Adequate command of the native language is the key pre-requisite in acquiring translation competence. Mastering the knowledge of lexical and grammar system, enriching general and special terminological lexicon and, as a result, developing the ability to extract the necessary information from the text and functionally and stylistically relevantly transfer it into the translating language are initial milestones in the process of shaping translation competence. The task is to be achieved in the context of special courses in stylistics of the Russian language and the culture of speech being part of the bachelor's cycle of educational program in thermal power engineering, or as a standard course in the curriculum of the additional educational program 'Translator in the area of professional communication' available for undergraduate and graduate students at the Department of Foreign Languages, Institute of Power Engineering at the National Research Tomsk Polytechnic University. As an efficient example at this stage can be practical exercises aimed at paraphrasing sentences and coherent passages in the native language without changing or modifying the content, the main idea and the style of the passage under study. As an alternative the sentence or the set of sentences can be restructured, but not 
changed contextually. The message and the function of the passage should be preserved and transferred by adequate means of the native language.

At a later stage these exercises are offered to students in the English language. The task becomes more sophisticated, and students are to analyse and evaluate that the content of the source passage is preserved in the target language, and the language means used to translate the text are adequate to the stylistic norm and functionally accepted in the context. Didactically this stage appears to be more complicated than exercises in the native language. The attention should be focused not only on the subject matter of the passage under translation, but also (and more important) on the process of decoding the information and understanding its sense. The suggested set of exercises is aimed at providing students practice in extracting the content centre (nucleus) of the passage in the interrelation of words and phrases constituting it and apply adequate means of translating language to transfer its sense completely and precisely.

Another important constituent for developing translation competence is a solid terminological background of the translator's profile, active operation of the widely used terms and terminological combinations in the area of thermal power engineering. The preference should be given to those terminological items which are frequently and widely used, are exact and precise in expression; also the emphasis should be made on their equivalents in the Russian language. The practice of enriching active terminological base is directly linked with abundant use of referential sources, terminological dictionaries, glossaries of special terms, electronic corpora and other online specialized services $[8,9$, $10,11]$.

To prove the importance of good command of terms we demonstrate a relatively rare phenomenon in the terminological sphere when 2 terms or terminological expressions can be translated absolutely identically, we mean the following terminological units - thermal power engineering and heat power engineering. By comparing their translation into Russian in several dictionaries we may still feel the slight difference in the scope of interpretation. In Collins Free Online Translator and in Lingvo Online Dictionary thermal power engineering is translated as 'тепловая энергетика' and heat power engineering - as 'теплоэнергетика'. The Electronic Dictionary Multitran contains the following translation of the above terms: thermal power - 'теплоэнергетика'; 'тепловая энергетика'; tech. 'тепловая мощность (энергосистемы)'; 'теплотворная способность'; 'тепловая энергия', and the terminological expression heat power engineering is translated as 'теплоэнергетика'.

The value of the correct use of terminological items can be proved by comparing very close in meaning terms in the area of power engineering, namely the synonymic row energy-power-capacity. The Electronic Dictionary Multitran provides the following translation of these terms: energy - gen. энергия, сила, мощность, энергоносители; есоn. электроэнергия; el.tech. потребленная электроэнергия; электропотребление; power gen. производительность; способность; tech. источник энергии; el. питание; capacity gen. ёмкость; вместимость; объём; пропускная способность; электрическая ёмкость; tech. нагрузка; выработка; el.tech. (электрическая) ёмкость; установленная мощность (электростанции); energ. (электрическая) мощность; (электрическая) производительность; (электрическая) пропускная способность; (электрическая) установленная мощность.

In Lingvo Online Dictionary энергия means 'energy' in physics and technically 'power'. Examples: cumulative energy - 'совокупная энергия', biomass energy 'энергия биомассы'. Also in Lingvo Online Dictionary power - 1. сила, мощь; 2. энергия, электроэнергия; 3. способность, возможность ... 13. мощность, производительность. Examples: high-power deep discharge - глубокий разряд повышенной мощности; absolute thermoelectric power - коэффициент 
термоэлектродвижущей силы; absorbing power - абсорбирующая способность; абсорбционная способность; поглощающая способность; сила поглощения. Capacity - вместимость, ёмкость, объём; capacity building - наращивание потенциала; capacity extension - наращивание ёмкости; capacity factor - коэффициент загрузки. Capacity in Collins Free Online Translator is rendered as 'мощность'. The ability to differentiate basic terms and correctly apply the knowledge of terminological system from the area of thermal power engineering assist students in choosing the appropriate option and strategy of solving translation problems.

\section{Creative tasks and projects aimed at mastering translation competence in thermal power engineering students}

The advanced level of mastering translation competence is realized within the context of the additional educational program 'Translator in the area of professional communication' delivered at the Department of Foreign Languages, the Institute of Power Engineering at the National Research Tomsk Polytechnic University, Russia. The curriculum includes courses in the use of Russian for the purpose of academic and research communication, abundant practice in mastering English language skills, courses in English lexicology, stylistics and pragmatics, and the most part of the curriculum is devoted to the theory and practice of written translation from English into Russian. Students are motivated to do translation projects and get involved in translation competitions. One of them is a traditional competition held under the support of the Russian National Committee Cigre, Youth Division [12]. The translation competition involves three rounds: first, written translation from English into Russian of the realistic research paper presented at the conference devoted to the modern trends and problems of thermal power engineering, second, presentation of the key aspects of the translated paper in English using the format of PowerPoint presentation, and third, written translation of an article focusing on trends and tendencies in power engineering in general and precise translation of a set of specific terms. If the first task is individual, that is every competitor receives an individual research paper for translation, then in the final round students are offered one common text for translation within a fixed period of time under the jury supervision. At all stages of the competition participants are allowed to use dictionaries and reference sources of their choice. Presentation of the translated paper is of vital importance not only for the purpose of evaluating the quality of translation but also promotes and deepens competitors' knowledge of the subject area and the way it is transferred in the English language.

At the level of the master's educational cycle students are prepared to be involved in individual or group projects that provide abundant practice in improving translation competence and perfecting communication in the English language. Example 1 is a research task-based project aimed at developing a virtual laboratory of thermal power engineering. The laboratory should be presented online and should give an idea of the stateof-the-art trends and developments in the area, be part of the online resources of students' department and optionally, can be recommended as a learning tool. Interactivity, feedback and visual appeal are welcomed. Example 2 is also a research task-based project aimed at designing a virtual translation environment supporting studies, which provides opportunities for producing student-generated learning materials and resources. Project team members are to decide which materials are of prior importance to ensure successful and user-friendly learning and how they can be used to help students benefit from the way they are presented. You may also want to consider possibilities of editing these materials by visitors (Web 2.0, wikis and others). The expose to realistic task-based projects can only be realized at an advanced level of efficient communication in English and close to expert application of translation competence. 


\section{Conclusion}

The efficiency of communication in English and well-developed translation competence are important components of successful professional career of the $21^{\text {st }}$ century engineering graduate. Basic practical tasks at the beginning of the learning process and more sophisticated creative assignments at a later stage provide necessary milestones in the process of becoming a confident translator in the area of thermal power engineering.

\section{References}

1. New pedagogies for deep learning: a global partnership - 2016. - Retrieved from: http://www.education.vic.gov.au/school/teachers/support/Pages/deeplearning.aspx

2. Fullan, M. Langworthy, M. A rich seam. How new pedagogies find deep learning. 2014. - Retrieved from: http: //www.michaelfullan.ca/wpcontent/uploads/2014/01/3897.Rich_Seam_web.pdf

3. Assessment and teaching of $21^{\text {st }}$ century skills. - 2010. - Retrieved from: http://www.cisco.com/c/dam/en_us/about/citizenship/socioeconomic/docs/ATC21S_Exec_Summary.pdf

4. PACTE research group. Departament de Traducció i d'Interpretació. - 2016. Retrieved from: http://grupsderecerca.uab.cat/pacte/en

5. A. Beeby, L. Berenguer, D. Ensinger, O. Fox, A. Hurtado Albir, N. Martínez Melis, W. Neunzig, M. Orozco, M. Presas, R. Vega, Acquiring translation competence: hypotheses and methodological problems of a research project. In: Investigating translation, ed. By A. Beeby, D. Ensinger, M. Presas (Universitat Autònoma de Barcelona Amsterdam, 2000)

6. A.Beeby, M.Fernández, O.Fox, A.Hurtado Albir, I.Kozlova, W.Neunzig, M.Presas, P.Rodríguez-Inés, L.Romero, Investigating Translation Competence: Conceptual and Methodological Issues Meta, 50, 609 (2005).

7. European standard. Translation services - Service requirements. - 2004. - Retrieved from: http://web.letras.up.pt/egalvao/prEN-15038.pdf

8. Collins Free Online Translator. - 2016. - Retrieved from: http://www.collinsdictionary.com/translator

9. Cambridge Dictionary. - 2016. - Retrieved from: http://dictionary.cambridge.org/

10. Lingvo Live. Online Dictionary from ABBYY. - 2016. - Retrieved from: https://www.lingvolive.com/

11. Electronic Dictionary Multitran. - 2016. - Retrieved from: http://www.multitran.ru/

12. Russian National Committee Cigre Youth Division. - 2016. - Retrieved from: http://www.cigre.ru/rnk/youth/ 